Article

\title{
Influence of Arabic and Chinese Rammed Earth Techniques in the Himalayan Region
}

\section{Paul Jaquin}

Integral Engineering Design, Tollbridge Studios, Bath, UK; E-Mail: pauljaquin@gmail.com

Received: 14 August 2012; in revised form: 24 September 2012 / Accepted: 8 October 2012 /

Published: 15 October 2012

\begin{abstract}
This paper discusses different rammed earth construction technique in Asia. Rammed earth construction techniques from China, Indian, Nepal and Bhutan are examined. It is shown that these techniques are demonstrably different from each other, and argued that the techniques may have developed independently. Case study structures are discussed and it is shown that with care it is possible to chart the development of both techniques both chronologically and geographically.
\end{abstract}

Keywords: rammed earth; formwork; rammer; Asia; Bhutan; Ladakh; Mustang, Hakka

\section{Introduction}

In this paper we compare different aspects of rammed earth construction, focusing mainly on the formwork support and the rammer. The findings presented in this paper are a result of the author's observations of a number of sites in Asia, and it is believed this is the first time such similarities and differences have been described. However, a detailed survey of many rammed earth structures has not been undertaken, and thus the conclusions, at this point, are tentative.

\section{Rammed Earth}

Rammed earth is a simple construction technique based on compacting earth between formwork to make a homogeneous wall. It has recently become popular in Australia, the USA and other parts of the world because it is recognized as a sustainable building material. Few realize the full extent of historic rammed earth construction and the variety of techniques used in the past. To build a rammed earth wall, a formwork box is constructed, and soil is taken from the ground and if necessary sieved to remove larger particles. Additives such as straw or lime may be mixed into the soil, which is then 
dropped into the formwork in layers, usually around $150 \mathrm{~mm}$ high. The layer is then compacted using a heavy rammer. Upon compaction of one layer, another layer of earth is placed in the formwork and the process repeated until the formwork is full. Upon completion of one horizontal level the formwork is moved vertically, the mass of standing wall being known as a lift.

\section{Rammed Earth Distribution}

It is probable that earth-building techniques developed independently in different parts of the world, and the earliest shelters probably utilized natural features such as caves, and the first earth buildings may have been extensions to natural features, such as mounds of earth at cave entrances or pits dug into the ground. The development of monolithic earth walls, such as rammed earth or cob is likely to have developed from such heaping of earth [1].

Rammed earth requires a mixture of sandy, silt and clay soil. This type of soil is found in various locations, but generally in relatively hilly areas, where it is possible for eroded sands, and alluvial clays and silts to be found together. As a result, rammed earth can be found at the edges of large river valleys, in mountainous regions where glacial till is found, and occasionally on river valleys at loess plains.

Rammed earth, and variations on it are common in the Himalaya [2], central Asia [3,4] and China [5]. The distribution of rammed earth around the world has previously been described [6], but the specific case of rammed earth in the Himalaya has only briefly been discussed [7]. It is hoped that by examining descriptions of rammed earth in the region, it is possible to elucidate slight differences in the construction types, the cultures from which they originate, and to therefore to potentially help to identify and recognize existing rammed earth buildings.

Specific case studies have been chosen, based on the author's experience and to show the varied types of rammed earth construction in Eastern Asia, and the various cultures which have influenced the rammed earth tradition. The examples chosen are those kingdoms along the length of the Himalayas, namely Ladakh, part of northern India and subject to both Buddhist and Islamic influences through history; Mustang a predominantly Buddhist kingdom, though part of Nepal; Bhutan, a country where rammed earth continues to be promoted as a traditional vernacular construction technique; and these are compared the rammed earth techniques found in parts of China such as Xian and Yunnan.

\section{Example Rammed Earth Construction}

\subsection{Ladakh}

The region of Ladakh lies on the Tibetan plateau to the north of the Indian subcontinent, at the western end of the Himalayas. To the north lie the former Soviet states of Kyrgyzstan and Tajikistan, to the west Afghanistan and Pakistan, and to the east China and Nepal. The region has acted as a melting pot of cultures.

Figure 1 shows a section of the wall of the fort at Basgo (Rabtan Lhartsekhar Castle). Basgo was the capital of Ladakh before 1357, and it is possible that the castle dates from this period [2]. The wall outer face forms a stepped batter, each lift slightly inset from the one below. Such a batter is 
constructed by the formwork for a higher lift being rested on the edge of the lower lift, each lift of rammed earth thus becoming progressively thinner towards the head of the wall.

Figure 2 shows the fort at Leh, Namgyal Tsempo (Victory Peak) which was constructed in 1555. The king who constructed it, Tashi Namgyal was one of the most successful kings of Ladakh, increasing the size of the kingdom and defeating Muslim invaders [8]. The castle shows two distinct construction techniques. A gap runs vertically through the face of the wall in the centre of the picture. This gap separates two distinct construction phases, with the phase to the left clearly showing holes to support formwork, while the phase to the right does not show any holes, indicating that the formwork must have been supported from the base of the wall. Both sections of wall step back as they rise, as seen at Basgo [9].

Figure 3 shows a copy of a Farsi manuscript, part of a larger collection held at the British Library and drawn around the middle of the 19th century describing all types of construction techniques in Srinagar at that time (possibly from the collection of William Moorcroft or Alexander Cunningham [10]). This manuscript clearly shows the type of formwork adopted the size and shape of the rammers, and other implements used in construction. The base of the formwork, within the stone layer shows horizontal support timbers (mechinales in Spanish) which support the vertical timbers restraining the formwork. When these mechinales timbers are remove they leave the characteristic 'putlog' or formwork support holes seen in the walls at Basgo. Unfortunately only one layer of construction is shown, rendering it impossible to determine how the next lift was formed. The rammer takes the form of a double ended timber, around $1.5 \mathrm{~m}$ long, with a thinner section in the centre.

Figure 1. Basgo fort, possibly constructed before 1357.

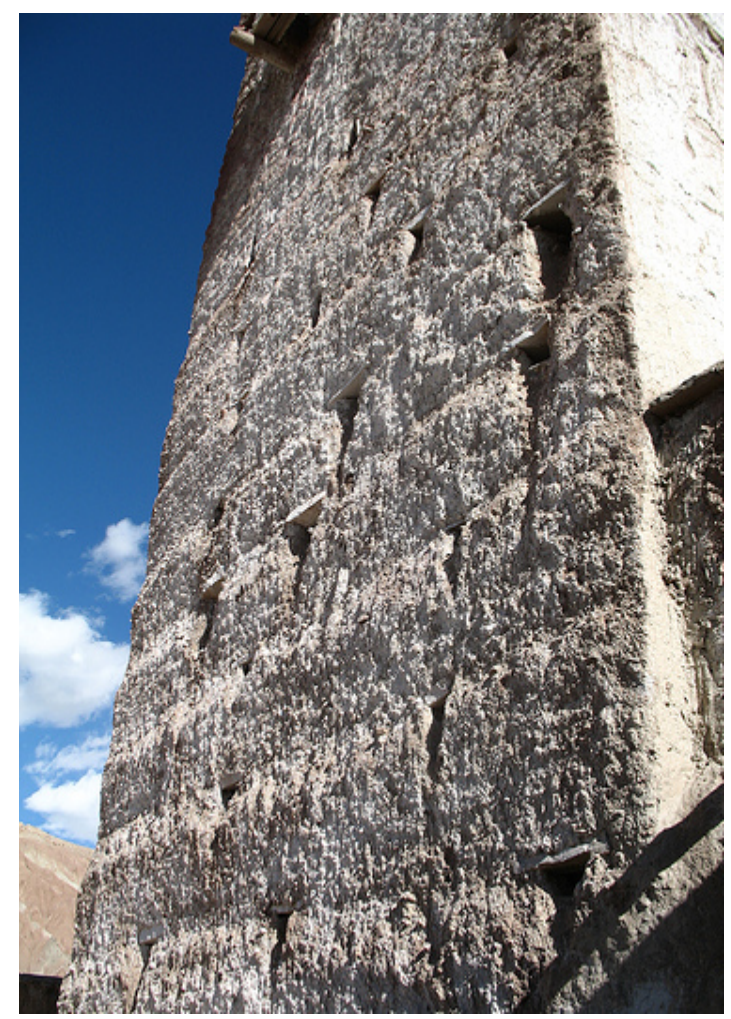


Figure 2. Leh fort, constructed around 1555.

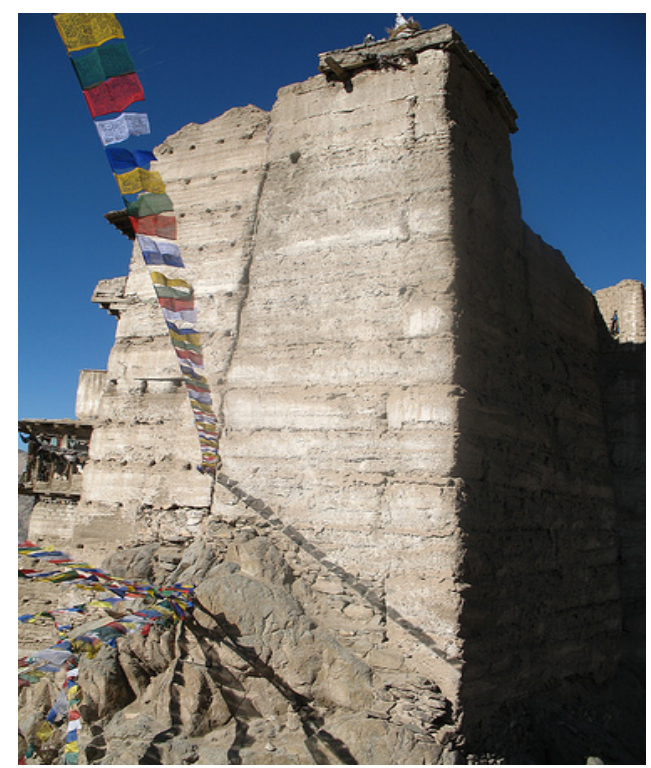

Figure 3. Farsi manuscript written in the mid-19th century in Srinagar, India. Author unknown, one of around 80 plates describing vernacular traditions [11].

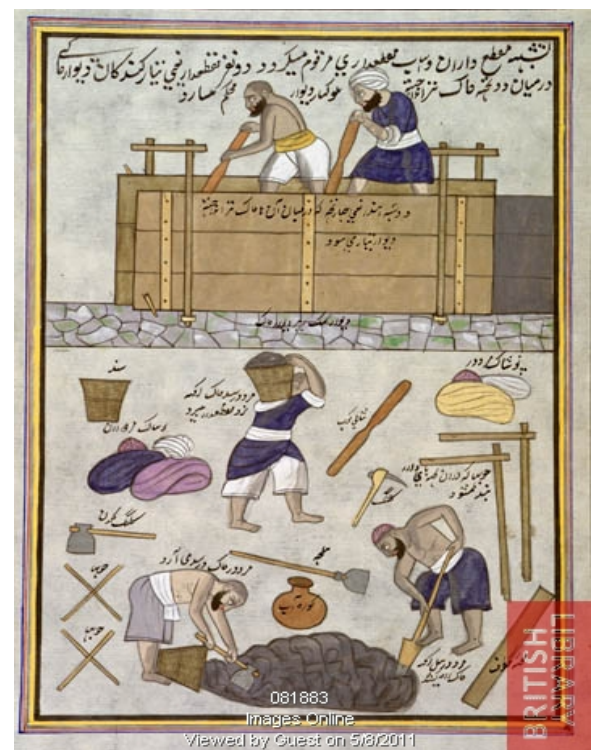

\subsection{Nepal: Mustang}

The kingdom of Mustang is at the western end of the Annapurna region of the Himalaya. The region is dry and arid, and rammed earth is a vernacular construction technique. Foreign visitors have been allowed to enter the kingdom of Mustang since 1991, but access to Upper Mustang and Lo Manthang requires a special permit. The examples here can be found in the town of Kagbeni, the gateway to the kingdom.

Figure 4 shows the monastery of Kag Chode Thupten Samphel Ling established in 1429 [12]. The rammed earth walls do appear to taper, but with significantly less of a step than seen in Ladakh. In addition, the walls contain many of the characteristic 'putlog' holes used to support formwork. It is 
also interesting to note that large timbers are embedded into the walls, which are likely to be provided to improve the seismic resistance of the structure.

Figure 5 shows modern rammed earth construction taking place in Kagbeni, but here the construction technique is different to that used in the monastery. Here vertical poles are fixed to the ground, and tied at the top by ropes. These timbers are tightened against the wall using wedges, and earth is rammed into place. The rammers are timber with cylindrical centers and double-headed, with one end round and the other flat, to enable ramming against the flat formwork.

Figure 4. Kag Chode Thupten Samphel Ling monastery, Kagbeni.

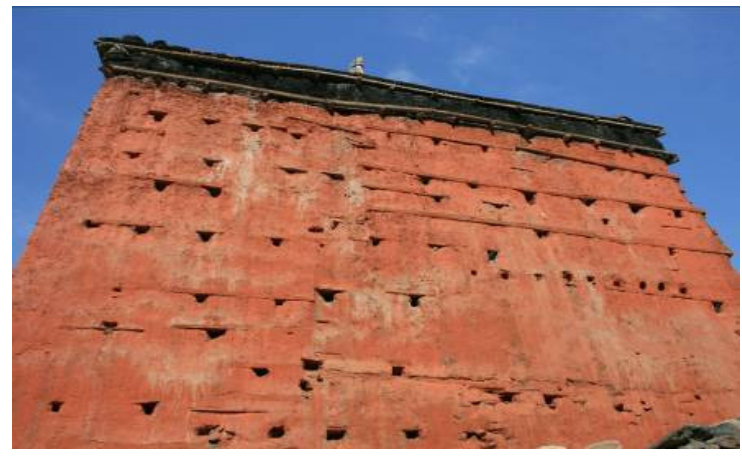

Figure 5. Modern rammed earth construction in Mustang.

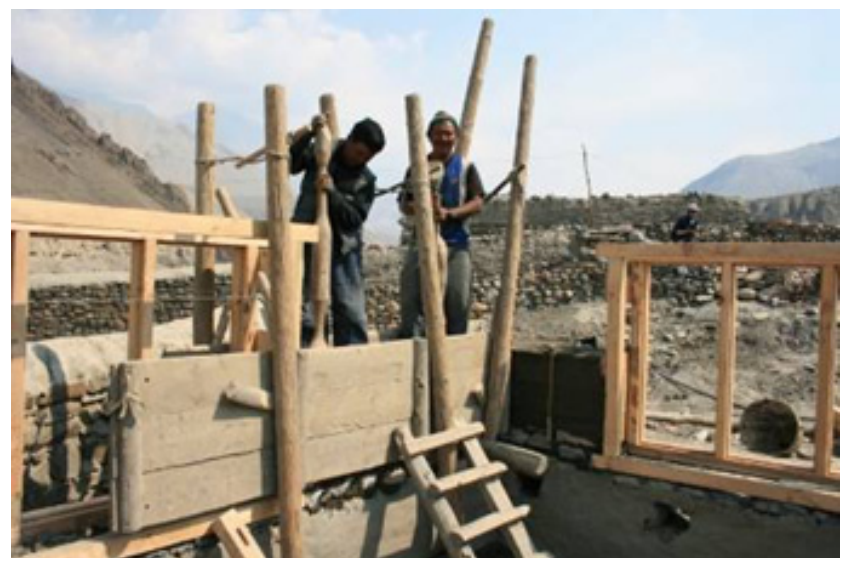

\subsection{Bhutan}

Bhutan is an independent kingdom at the eastern end of the Himalayas, where rammed earth is promoted as a vernacular construction technique. Figure 6 shows the rammed earth section of Kyichu Lhakhang monastery. The monastery itself is probably the oldest in Bhutan, and this building is thought to be around 300 years old [13]. The rammed earth here shows the characteristic 'putlog' holes used to support formwork, and the wall is vertical, rather than tapered towards the head.

Figure 7 shows modern rammed earth construction in central Bhutan. The formwork here is supported on timbers running through the center of the wall, leaving putlog holes. The forms are supported using a solid timber piece over the top of the formwork box, fixed to the head of vertical timbers, which have wedges driven between them to keep the formwork boards apart. The timber rammer is one ended, with a thin handle and a heavy round timber end. 
Figure 6. Rammed earth section of Kyichu Lhakhang monastery, built around 1700.

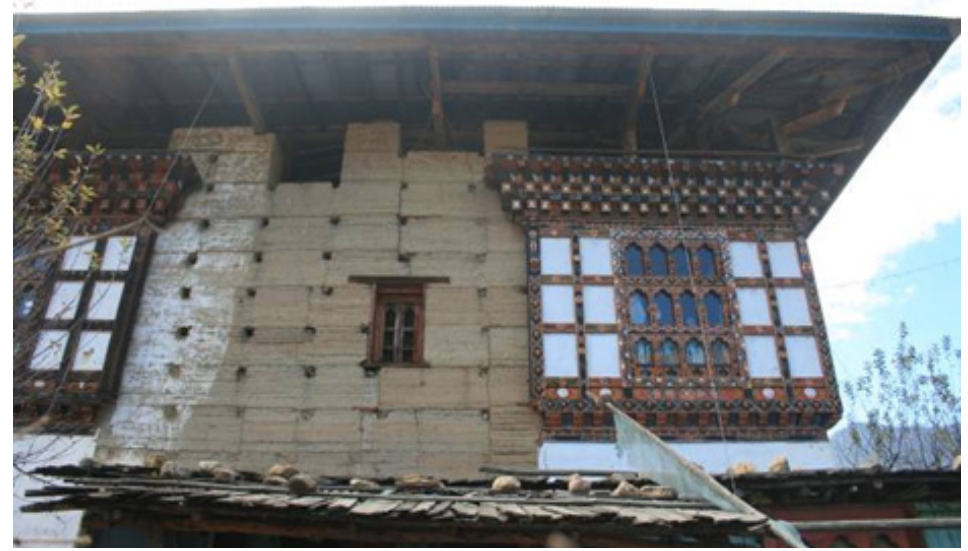

Figure 7. Modern rammed earth in Bhutan.

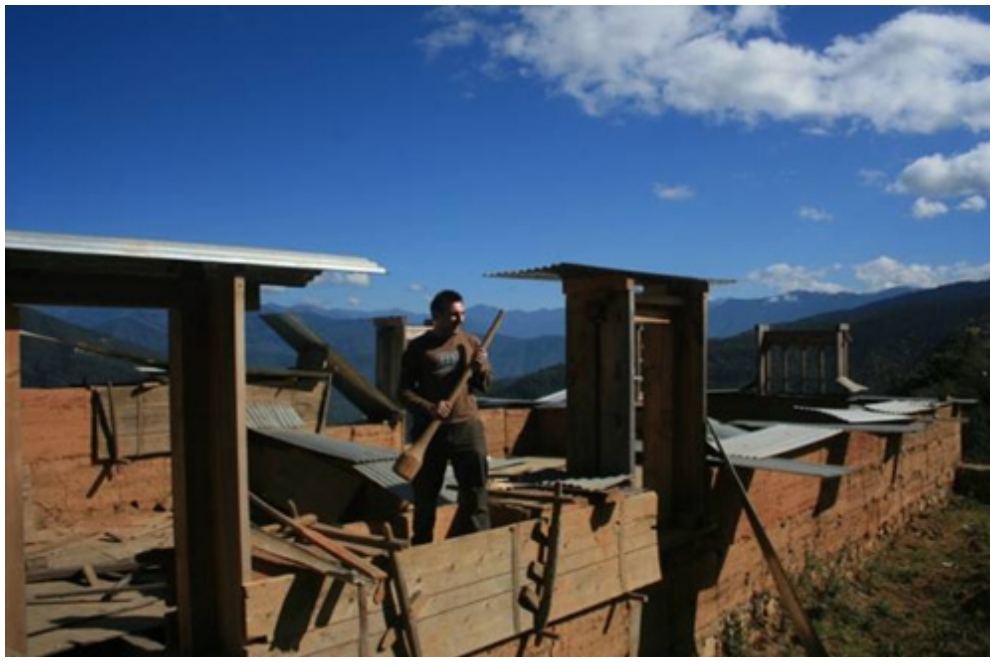

\subsection{China}

Rammed earth has a long tradition in China, most notably being used for the construction of many of the sections making up the 'Great Wall' of China [14]. Figure 8 shows a line drawing found in a book by Joseph Needham [15]. Here the formwork appears to be supported from the ground, and the forms are relatively thin. The end of the formwork appears to be the full height of the building. The rammers comprise rods with a horizontal handle at one end, and a weight at the other. Figure 9 shows a rammed earth construction in Xi'an and appears very similar to that shown in Figure 8. The formwork here comprises individual timbers which appear to be moved vertically as ramming continues, and leave a characteristic ridge and trough pattern in the face of the wall. The rammers in Figure 9 also have horizontal handles and weighted ends, as Figure 8. Figure 10 shows modern rammed earth construction in Yunnan province. This large scale house is constructed using formwork which is supported on vertical posts driven into the ground, and slowly advances up the building as the ramming continues. The timber rammer, shown in Figure 11 is two ended, with a circular and a flat end. 
Figure 8. Traditional Chinese rammed earth construction [4].

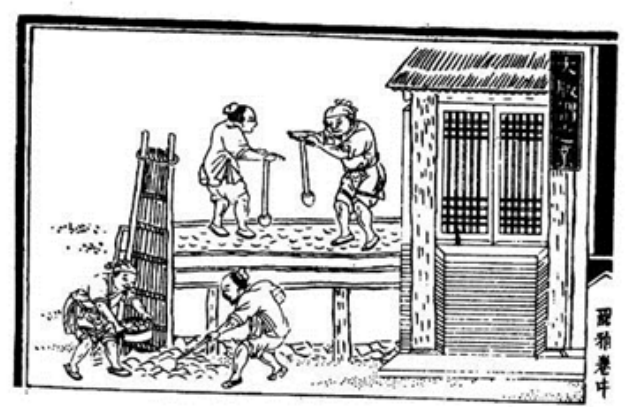

Figure 9. Modern rammed earth construction, Xi'an region [16].

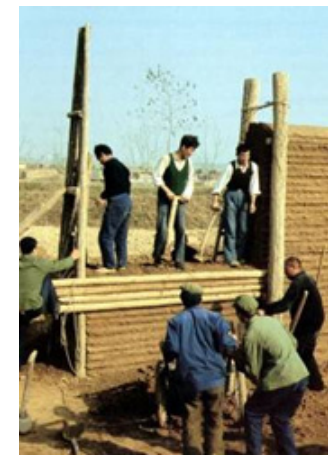

Figure 10. New rammed earth building in Shangri-La (Zhongdian) County, Yunnan [17].

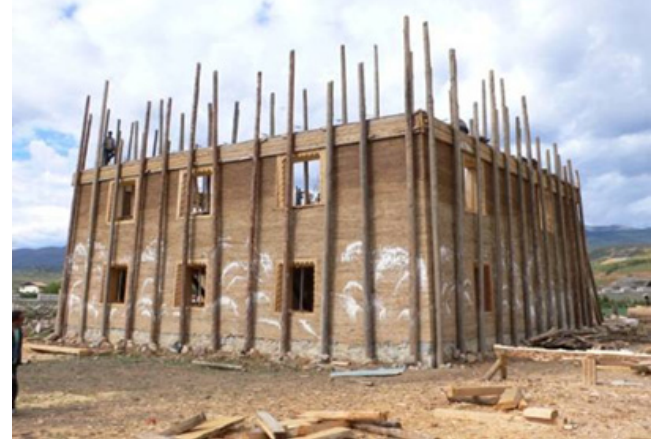

Figure 11. New rammed earth building in Shangri-La (Zhongdian) County, Yunnan. Rammer detail [17].

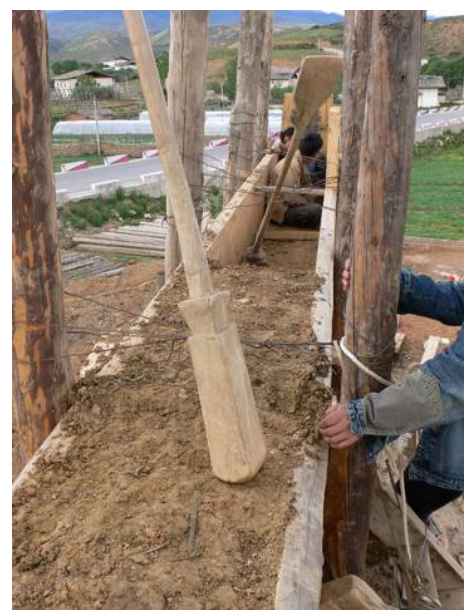




\section{Discussion}

Human ingenuity means that there are many solutions to the same problem; this is seen in the development of the rammed earth technique, and in the solutions to supporting formwork and ramming earth. The small study sample means that it is impossible to map and thus infer different rammed earth techniques used in different geographical locations, and this is likely to be driven by a number of factors, such as the availability of other materials, size and skill of the workforce. Nonetheless, it is possible to perhaps draw some very broad conclusions about rammed earth techniques which may be used as the basis for further study.

\subsection{Formwork Support}

There are two schools of thought regarding support to the formwork during construction. The formwork is either supported using timbers which are threaded through the wall (named mechinales in Spanish, there is no equivalent English word), or on posts which are fixed prior to construction. There are advantages and limitations to each strategy. Where horizontal timbers are placed through the wall, these can be removed upon completion of the wall, and to facilitate that, a further timber or stone is required above the formwork support timber-acting as small lintel to support the wall above [9]. Upon removal of the timber, a hole is left in the wall, which allows air through which may not be desirable. Vertical posts remove the need for holes through the body of the wall; however do require a good bearing surface at the base of the wall. Timbers are placed through the body of the wall mean that a wall may be constructed on steep inclines such as seen in Figure 1. By using a stepped batter on the wall as it rises, there is no need for timbers placed through the body of the wall (though they are provided at the wall in Leh). Each subsequent lift can be placed on the previous, meaning that the formwork need only be supported to resist its moving outward, rather than against gravity. Where mechinales timbers are used, they tie the base of the formwork lift together, a role which is fulfilled by the wedges (see Figure 7) where vertical poles are used.

\subsection{Rammer}

It is difficult to infer the type of rammer used from the standing structures, therefore we must consider historic documents or contemporary construction practices. These indicate that there are many different rammer typologies, and although broadly similar, and designed to fulfill exactly the same requirements, the rammers do differ considerably. It is impossible to infer from these documentary sources whether the rammer is simply lifted and dropped, or if a downward force is applied. Double ended rammers, as seen in the Srinagar manuscript, and used in modern Mustang, offer the ability to compact earth at the edges of the formwork, at the expense of being longer and therefore heavier. Single ended rammers do not reach to corners of formwork, and are shorter and thus lighter, though it is perfectly possible that other, more specific rammers may be used. The reason for the choice of different rammers is not immediately obvious, though the availability of different types of timber is a possible explanation. 


\subsection{Distribution and Spread of the Techniques}

The aim of this paper is to begin a dialogue on the different typologies of rammed earth found in this region, to enable further identification of different types of building techniques. It is perfectly possible that, for example, both types of formwork support were adopted at the same time, or used differently from location to location, with one mason favoring one construction type and another a different method. Likewise, the choice of rammer may be personal, with a myriad of types available and personal preference being the overriding factor. However, it is possible to draw some broad conclusions:

Tapering walls are not generally found in European and North African rammed earth building [18], and appear to be a development of Eastern Asia, being found in Ladakh and Mustang. Formwork supported using the wall leaves characteristic putlog holes through the wall. This is a common feature of European and North African rammed earth [19]. Construction of vertical posts against which formwork is fixed is found in Xian and in Bhutan. It would appear too difficult to construct tapering walls using vertical posts fixed at the ground. Figure 8 appears to show a tapering wall using vertical timbers fixed to the ground, but the photographic evidence from Figure 5, 10 and 11 would suggest that vertical walls are built using timbers fixed to the ground. Therefore we may identify two distinct types of rammed earth construction, and may surmise that formwork supported externally on vertical posts may have originated in China, while formwork supported on walls may have developed elsewhere. Much further study and a review of many more buildings are required before this hypothesis can be accepted.

The development of rammers is more difficult to describe, as it is virtually impossible to infer the rammer used from a standing building. However, observation of current construction techniques and historic documents mean it is possible to observe that double ended rammers tend to be used in 'North African' rammed earth construction, while single ended rammers are used in Chinese construction.

The Himalayan kingdoms of Ladakh, Mustang and Bhutan have all have historic links to Tibet and Buddhist ideas and architectural principles flowed between them [20]. Ladakh was invaded by Muslims coming from modern Pakistan in the 16th century [21]. It is therefore possible that a more North African rammed earth technique passed from the Muslims of North Africa, through the Islamic Caliphate to Ladakh [22], and therefore it is possible to view North African rammed earth in Ladakh. It has been suggested that rammed earth structures in at Karsha old castle nearby Zanskar were constructed as 16th century additions to the 11th century buildings [8]. Although far from conclusive, it is interesting to note that rammed earth does not appear to have been used in this part of Zanskar before the 16th century.

Once these ideas had become ingrained into Ladakh culture, it is possible they were spread into Tibet and then out to Mustang and Bhutan. By the 19th century, when Figure 3 was drawn, such North African rammed earth techniques were obviously common in Srinagar, though the author has not found many examples of 19th century rammed earth in Ladakh. Modern construction in Bhutan, using vertical timbers, appears to follow techniques found in Xi' an and in Yunnan, and thus borrows more from the Chinese methods. 


\section{Conflict of Interest}

The author declares no conflict of interest.

\section{References}

1. Jaquin, P.; Augarde, A. Earth Building: History, Science and Conservation; BRE Press: Watford, UK, 2012.

2. Hurd, J. Observing and Applying Ancient Repair Techniques to Pisé and Adobe in Seismic Regions of Central Asia and Trans-Himalaya. In Proceedings of the Getty Seismic Adobe Project 2006 Colloquium, City, Country, Day Month 2006; pp. 101-108.

3. Schroeder, H.; Schwarz, J.; Chakimov, S.A.; Tulaganov, B.A. Traditional and Current Earthen Architecture in Uzbekistan. In Proceedings of the Earthen Architecture in Iran and Central Asia: Its Conservation, Management, and Relevance to Contemporary Society, Institute of Archaeology, University College London, London, UK, 12-13 November 2005.

4. Cooke, L. Earthen Building Materials and Techniques at Merv, Turkmenistan. In Preprints 4th International Conference on Building with Earth; Dachverband Lehm e.V.: Leipzig, Germany, 29-30 October 2004.

5. Houben, H.; Guillaud, H. Earthen Architecture: A Comprehensive Guide; Intermediate Technology Development Group: London, UK, 1994.

6. Jaquin, P.A.; Augarde, C.E.; Gerrard, C.M. Historic Rammed Earth Distribution. Int. J. Architect. Herit. 2008, 2, 377-400.

7. Howard, N. The Fortified Places of Zanskar. Recent research on Ladakh 4 and 5. In Proceedings of the Fourth and Fifth International Colloquium on Ladakh; Osmaston, H., Denwood, P., Eds.; Publisher: Bristol, UK, 1995.

8. Ghani Sheikh, A. A Brief History of Muslims in Ladakh. Recent research on Ladakh 4 and 5. In Proceedings of the Fourth and Fifth International Colloquium on Ladakh; Osmaston, H., Denwood, P., Eds.; Publisher: Bristol, UK, 1995.

9. Jaquin, P.A. Analysis of Historic Rammed Earth. PhD Thesis, University of Durham, Durham, UK, 2008.

10. Cunnginham, A. Ladakh-Physical, Statistical and Historical; SK Enterprises, New Delhi, India, 2006.

11. Image online. India Office collection, British Library, London. Available online: https://imagesonline.bl.uk/?service=search\&action=do_quick_search\&language=en\&q=Add.Or.1 717 (accessed on 28 August 2012).

12. Traditional date of founding of the monastery. Available online: www.kagchode.com (accessed on 28 August 2012).

13. Seeds of Faith: A Comprehensive Guide to the Sacred Places of Bhutan; Thinley, L.P., Wangdi, P., Eds.; KMT Publishers: Thimphu, Bhutan, 2008; pp. 106-107.

14. Lovell, J. The Great Wall. China Against the World, 1000BC-AD 2000; Atlantic books: London, UK, 2006. 
15. Needham, J. Science and Civilization in China; Cambridge University Press: Cambridge, UK, 1954.

16. Maini, S. Auroville photograph collection. Auroville Earth Institute, Auroville, India. Personal Communication. 2003.

17. Rutherford, C. Personal Communication. 2005.

18. Jaquin, P.A.; Augarde, C.E.; Gerrard, C.M. Historic Rammed Earth Structures in Spain: Construction Techniques and a Preliminary Classification. In International Symposium on Earthen Structures, Bangalore, India, 22-24 August 2007.

19. Authors. Análisis Comparativo de las Intervenciones en Fábricas de Tapial. El Caso de las Fortificaciones. La Arquitectura Construida en Tierra. Tradicion e Innovación; Universidad de Valladolid: Valladolid, Spain, 2010; pp. 141-154.

20. Teltscher, K. The High Road to China; Bloomsbury Publishing: London, UK, 2006.

21. Hourani, A. A History of the Arab Peoples; Faber and Faber: London, UK, 1991.

22. Ruthven, M.; Nanji, A. Historical Atlas of the Islam World; Oxford University Press: Oxford, UK, 2004.

(C) 2012 by the authors; licensee MDPI, Basel, Switzerland. This article is an open access article distributed under the terms and conditions of the Creative Commons Attribution license (http://creativecommons.org/licenses/by/3.0/). 